\title{
The analysis of EDM electrodes wear in corners and edges
}

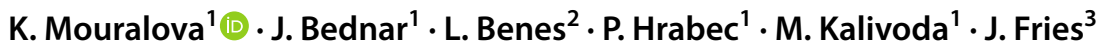

Received: 11 June 2020 / Revised: 1 September 2020 / Accepted: 5 October 2020

(c) Wroclaw University of Science and Technology 2020

\begin{abstract}
Die-sinking electrical discharge machining is an unconventional technology that allows to machine all at least minimally electrically conductive materials regardless of their physical and mechanical properties. Despite the fact that it is not a conventional technology, the tool gets also worn out, which is a tool electrode. The wear of the electrode does not only mean its loss but also the degradation of the shapes that are transferred to the resulting workpiece. For this reason, a design of experiments was conducted with 6 input factors, 2 were categorical: the electrode material (copper, graphite) and workpiece material (steel 1.2363 and steel 1.2343ESR) and 4 were numerical: Open-voltage, Pulse current, Pulse on-time, and Pulse off-time. In the framework of this design of experiments, the wear of the used graphite and copper electrodes at their corners and edges was evaluated, which was made possible by the use of electron microscopy and the use of approximation circles. Furthermore, the eroding speed, the topography of the machined samples, and the morphology of the surfaces of the used electrodes were investigated. It has been recognized that the use of a graphite electrode will allow for more accurate workpiece shapes and less wear.
\end{abstract}

Keywords EDM $\cdot$ Electrical discharge machining $\cdot$ Wear $\cdot$ Design of experiment $\cdot$ Electrode $\cdot$ Corners

\section{Introduction}

Die-sinking electrical discharge machining (EDM) is a technology operation that is indispensable in many industries, such as the automotive, aerospace, military, and medical industries. Machining is carried out without the contact of the tool (electrode) with the workpiece; therefore, there are no conventional cutting forces and the resulting workpiece is not stressed by them. This allows producing thin-walled profiles from soft materials which are conventionally very difficult to manufacture [1]. It is possible to machine all at least minimally electrically conductive materials regardless of their toughness, hardness, or mechanical properties. Workpieces can, therefore, be machined to final dimensions only after heat treatment. This avoids dimensional

K. Mouralova

mouralova@fme.vutbr.cz

1 Faculty of Mechanical Engineering, Brno University of Technology, Brno, Czech Republic

2 Faculty of Mechanical Engineering, Czech Technical University in Prague, Prague, Czech Republic

3 Department of Production Machines and Design, Technical University of Ostrava, Ostrava, Czech Republic and volume changes in the part. A wide range of materials can be machined using EDM, from polycrystalline diamond (PCD) coated tools, ceramics, composite materials, silicon, to soft aluminum alloys used in the aerospace industry $[2,3]$.

However, during the erosion process, the material is also removed from the tool electrode by eroding, and not just from the workpiece. For this reason, it is necessary to carefully examine the wear status of the tool electrode, since the degradation of the shape of the electrode results in degradation of the desired shape of the workpiece [4].

Bleys [5] focused on making up an advanced method of wear compensation, where he tried to combine the anticipated compensation with the real-time. That was indispensable for the exact machining using milling EDM. This new method might be employed while machining the blanks in the cases when the accurate shape cannot be predicted beforehand. Luis [6] studied the electrode wear and the material removal rate using silicon carbide as a study material. In their research, they focused only on 5 design factors, such as pulse time, intensity, duty cycle, dielectric flushing pressure, and open-circuit, focusing just on the finish stages. Tsai [7] researched how thermal properties influence the electrode wear. It was detected that the boiling point plays a great role in the micro-EDM wear mechanism. This factor 
cannot be ignored while dealing with the electrode material's wear resistance. The date output received during the experiment displays a strong correlation with the new index. Khan [8] attempted to assess the electrode wear comparing it along the cross-section and the length. Aluminum and mild steel with copper and brass electrodes were used as a material for the research. It was found out that voltage and especially current increase the electrode wear, which is relatively higher in the cross section than along its length. However, the steel machining with a brass electrode showed the highest ratio of the wear. Narasimhan [9] also studied the tool wear compensation focusing on the wear techniques used both for macro- and micro-EDM machining. They tried to create a tool path to process a desired surface. The effective tool path is influenced by machining parameters, material, and part feature. They also demonstrated the analysis of the compensation techniques of the tool wear. Klocke [10] analyzed the electrode wear together with the material removal rate employing five different graphite kinds with various physical characteristics, such as grain size, thermal conductivity, and electric resistance. During the experiments, they mainly focused on the specific wear behavior connected with those physical characteristics of the graphite. Yin [11], while studying the tool electrode wear, tried to make up a new method that would be able to decrease the electrode wear and abolish the enormous electrolytic-erosion in an effective way. To achieve this, they employed electrolyte as machining fluid and used the electro-deposition for compensation of tool electrode wear while the machining. Torres [12], having used Inconel 600 alloy as an investigation material, focused on the analysis of the effect of EDM parameters on the electrode wear, material removal rate, and surface finish. During the experiment, they took into account such factors as polarity, intensity, pulse time, and duty cycle. According to the outcomes of the experimental results, the positive polarity results in higher material removal rate, while the negative one causes the lower Ra values. Maradia [13] studied the carbonaceous layer which creates the electrode surface while EDM with low wear settings and investigated its formation during the erosion. It was monitored that the microstructure of the layer depends on the parameters, such as pulse duration and applied current. Kumar [14] investigated the mechanical properties, tool wear rate, and material removal rate during the EDM machining, using Aluminum 2618 strengthened by $\mathrm{AlN}, \mathrm{Si}_{3} \mathrm{~N}_{4}$, and $\mathrm{ZrB}_{2}$ as an experimental material. It was found out that the $\mathrm{wt} \%$ rises proportionally with the mechanical properties. To analyze the machining characteristics of hybrid composites, a Taguchi's design of experiment was employed in the study.

Electrical discharge machining is a fundamental technological operation, so there is a never-ending effort to improve the performance characteristics of this machining process, in particular in the form of material removal rate, surface quality, and dimensional accuracy or reduction in tool electrode wear. Extensive research has been conducted to analyze the machinability and defect occurrence of Hardox [15], Creusabaro [16], X210Cr12 steel [17], and Ampcoloy copper alloy [18] to examine in detail all the input factors affecting the erosion process of various types of materials. The purpose of this study was a comprehensive analysis of the wear of copper and graphite electrodes in the corners while machining 1.2343ESR and 1.2363 steels. The wear of eroding electrodes for macromachining in their corners has never been investigated. However, knowing the condition of the electrode wear is crucial for the production of workpieces according to the required dimensions in a given accuracy. Another purpose of this study is to try to use the electrodes as economically as possible, depending on the required surface finish quality and shape accuracy.

\section{Experimental setup and material}

\subsection{Experimental material}

The samples for the experiment were made of two types of alloyed steels namely 1.2363 and 1.2343ESR. 1.2363 steel is $\mathrm{Cr}-\mathrm{Mo}-\mathrm{V}$ alloyed and has a chemical composition given by the standard in wt $\% .1 \% \mathrm{C}, 0.25 \% \mathrm{Si}, 0.6 \% \mathrm{Mn}, 5.15 \% \mathrm{Cr}$, $1.05 \% \mathrm{Mo}, 0.2 \% \mathrm{~V}$, and Fe balance, and 1.2343ESR steel has a chemical composition in wt $\% .0 .38 \% \mathrm{C}, 1 \% \mathrm{Si}, 0.4 \% \mathrm{Mn}$, $5.3 \% \mathrm{Cr}, 1.2 \% \mathrm{Mo}, 0.4 \% \mathrm{~V}$, and Fe balance. 1.2363 alloyed steel has high-dimensional stability during heat treatment, forming temperature of $1050-850{ }^{\circ} \mathrm{C}$, the annealed hardness of $230 \mathrm{HB}$ and achievable hardness of 57-63 HRC. It is characterized by high toughness, abrasion resistance, good machinability, and hardenability, and also suitable for nitriding. It is used for cutting and pressing tools for medium thickness materials, edge tools, thread rolling dies, and longitudinal and circular shears. 1.2343ESR steel is characterized by high hardenability and toughness, and has very good thermal conductivity, resistance to hot cracking, and low sensitivity to rapid temperature changes. It has a maximum strength of $770 \mathrm{~N} / \mathrm{mm}^{2}$ and a hardness of 229 $\mathrm{HB}$, has a uniform and good machinability, and is highly polishable and suitable for nitriding. It is universal steel for hot working. It is used for hot pressing tools and dies casting tools, light metal processing tools, forging and pressing dies, shaping parts of moulds, plastic processing screws, and plastic injection moulds. For the experiment, a $10 \mathrm{~mm}$ thick starting semi-product plate was used, which is shown in Fig. 1b, wherein the microstructure of the semi-product is shown in Fig. 1c,d. 


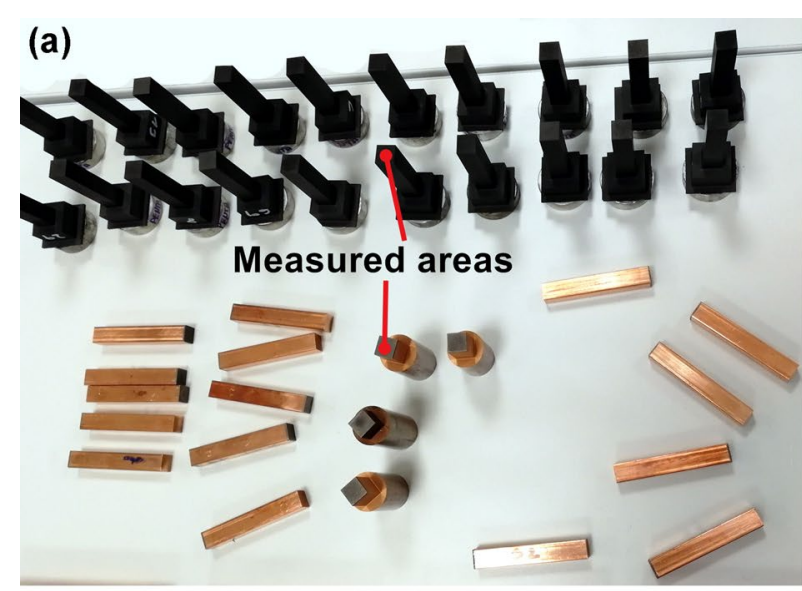

(b)
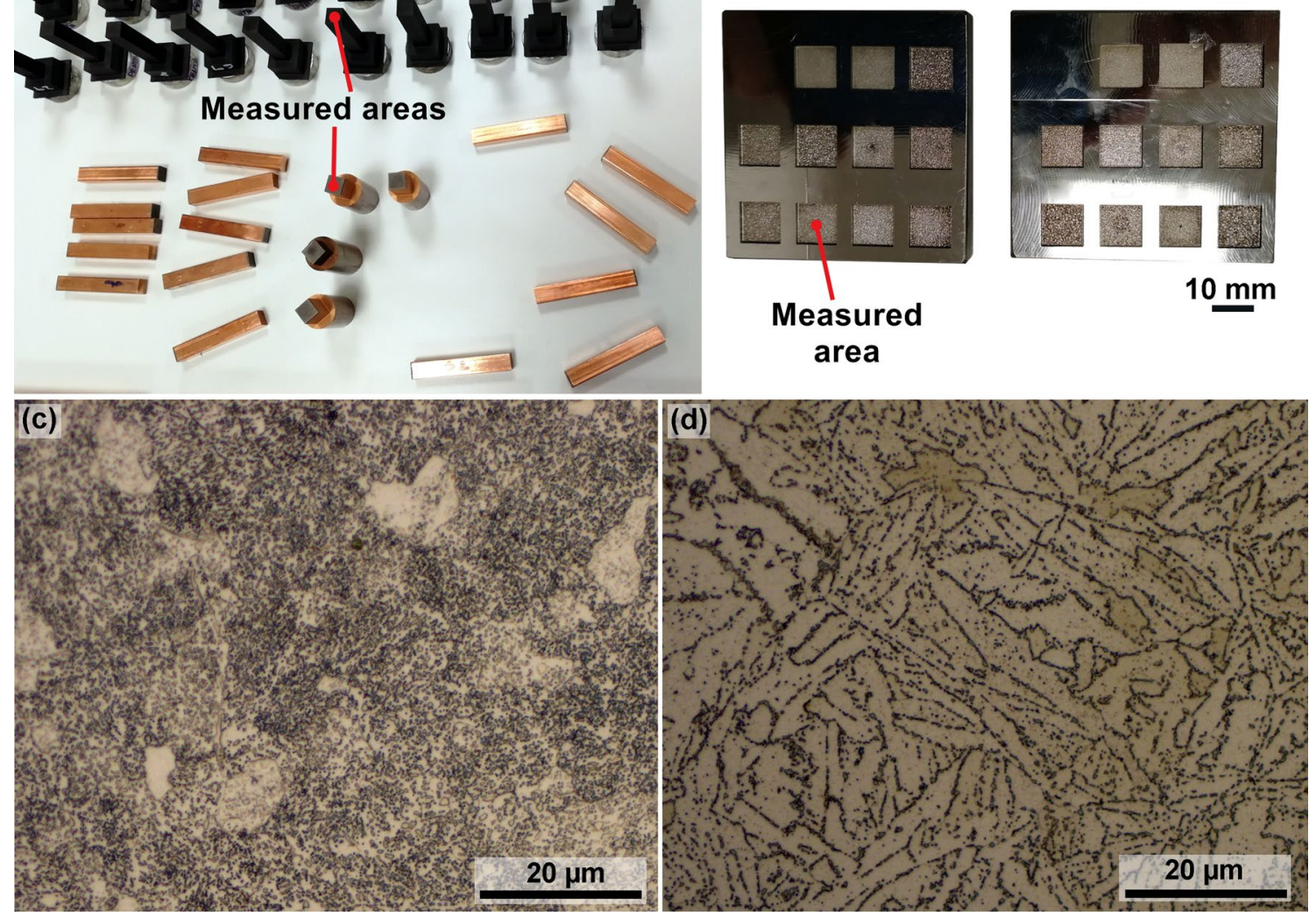

Fig. 1 a Graphite and copper electrodes used for sample production, b samples produced, $\mathbf{c}$ microstructure representation of 1.2363steel, and d microstructure representation of 1.2343ESR steel

\subsection{EDM machine setup}

All specimens were manufactured on a 433GS type EDM machine supplied by PENTA and fitted with a P-MG1marked generator. Each sample was machined with a completely new $10 \times 10 \mathrm{~mm}$ graphite or copper electrode, as shown in Fig. 1a. During the machining, all samples were submerged in kerosene. The eroding depth of each sample was always $1 \mathrm{~mm}$.

A design of experiments (DoE) was created to monitor the eroding speed, electrode wear, eroded shapes accuracy, topography change, and defect occurrence. A design of experiments is a systematic change of process inputs to model process outputs. In our case, we have 6 input factors, 2 are categorical: electrode material (Electrode) and workpiece material (Workpiece), and 4 are numerical: open-voltage $(U)$, pulse current $(I)$, pulse on-time $\left(T_{\text {on }}\right)$, and Pulse off-time $\left(T_{\text {off }}\right)$. The Workpiece input parameter is labeled with 1 for 1.2363 steel and 2 for 1.2343ESR steel. A two-level half-factorial design of experiment with one replication in the factor part and four replications at the central points was used. In total, $2^{6-1}=32$ runs (partial experiments) at factor points and $2^{2} \cdot 2=8$ runs at central points, because categorical variables do not have a central level and should be measured twice for all extremelevel combinations. There were altogether 40 runs, with the limit values of the input parameters given in Table 1 and the machining input parameters for all 40 runs are shown in Table 2. Since the EDM does not allow a direct adjustment of the eroding speed, but the speed is always the result of the setting of the individual eroding parameters, this speed was read from the machine display and entered into Table 2 to allow its evaluation. The material of the electrodes was selected on the basis of research by $\mathrm{Hu}$ [25]. This setting for each parameter was identified on the basis of the multiple previous tests and also on the recommendation of the machine manufacturer. 
Table 1 Limit values of input parameters for the design of the experiment

\begin{tabular}{lllllll}
\hline Parameter & Material of electrode & Material of workpiece & $\begin{array}{l}\text { Open } \\
\text { voltage } \\
(\mathrm{V})\end{array}$ & $\begin{array}{l}\text { Pulse } \\
\text { current } \\
(\mathrm{A})\end{array}$ & $\begin{array}{l}\text { Pulse } \\
\text { on-time } \\
(\mu \mathrm{s})\end{array}$ & $\begin{array}{l}\text { Pulse } \\
\text { off-time } \\
(\mu \mathrm{s})\end{array}$ \\
\hline Lower level & Copper & $\begin{array}{l}1.2363 \\
(1)\end{array}$ & 160 & 10 & 50 & 35 \\
$\begin{array}{l}\text { Central level } \\
\text { Lower level }\end{array}$ & Graphite & $1.2343 \mathrm{ESR}(2)$ & 280 & 20 & $100 *$ & $80^{*}$ \\
\hline
\end{tabular}

*The last two numeric parameters do not behave linearly, so the centres have been shifted. Since it is measured at only three levels, this offset can be seen as a non-linear transformation of input variables

\section{Results and discussion}

\subsection{Experimental methods}

All experimentally produced samples were cleaned in an ultrasonic cleaner and analyzed using an LYRA3 Electron Scanning Microscope (SEM) from Tescan. This equipment was equipped with an energy-dispersive X-ray detector (EDX), which allowed the study of the change of the chemical composition of the surface by die-sinking EDM. The surface topography was studied using the Dektak XT contact 3D profilometer supplied by Bruker. The measured data were then processed in the Vision 64 software.

\subsection{The surface topography of the machined samples}

The analysis of the surface topography in relation to the setting of machine parameters is necessary, especially in cases where the part is machined only by EDM without the subsequent finishing technology. For this reason, two surface topography parameters were evaluated in this experiment: arithmetical mean deviation of profile (Ra) and arithmetical mean height $(\mathrm{Sa})$. All parameters were evaluated using the Dektak XT contact 3D profilometer supplied by Bruker according to the corresponding standard for the area parameters ISO 25178-2 [19] and profile parameters ISO 4287 [20]. Five random places on each sample were selected for the measurement and an average was created from these values. The measured areas are highlighted in Fig. 1.

The evaluated surface topography parameters $\mathrm{Ra}$ and $\mathrm{Sa}$ of the individual samples were compiled into the graph, as shown in Fig. 2. During the design of experiments, the use of two types of electrodes (graphite, copper) while the machining of two types of steels $(1.2363,1.2343 \mathrm{ESR})$ was tested, and it is clear from the graph that the overall lower and also the lowest values of the examined parameters Ra and Sa were achieved with graphite electrode machining. For 1.2343ESR steel in Sample $29(U=280 \mathrm{~V}, I=10 \mathrm{~A}$, $\left.T_{\text {on }}=50 \mu \mathrm{s}, T_{\text {off }}=35 \mu \mathrm{s}\right)$, where the Ra value was only $4.4 \mu \mathrm{m}$, and for 1.2363 steelin Sample $19(U=160 \mathrm{~V}, I=10$ A, $T_{\text {on }}=50 \mu \mathrm{s}, T_{\text {off }}=35 \mu \mathrm{s}$ ) when the Ra value was only
$5.4 \mu \mathrm{m}$. However, these Ra values are relatively high compared to AISI P20 steel erosion also with a copper electrode, with the lowest Ra value of the produced sample being only $1.8 \mu \mathrm{m} \mathrm{[21]} \mathrm{and} \mathrm{a} \mathrm{graphite} \mathrm{electrode} \mathrm{with} \mathrm{the} \mathrm{lowest} \mathrm{Ra}$ value of $1.6 \mu \mathrm{m}$ [22].

\subsection{Analysis of electrode surface morphology}

In all cases, a secondary electron detector (SE) was used for imaging, and the samples were always studied at 500 $\times$ magnification followed by $1500 \times$. The measured areas are highlighted in Fig. 1.

Due to the effect of the individual electric discharges, a large number of craters are formed on the surface of the electrode being machined by EDM and the tool electrode, as shown in Fig. 3a. Compared to craters on the workpiece surface [23], however, the craters on the electrode surface are significantly shallower and less pronounced. In addition, a large amount of eroded material from the workpiece adheres to the tool electrode, as evidenced by an analysis of the chemical composition of the surface on the working part of the electrodes made of both graphite and pure copper. There are also several carbon-covered places on the copper electrode, indicating torn places from the discharge. The amount of the adhered eroded material that is adhering to the workpiece is visibly greater on the surface of the graphite electrode, where the iron forms solid particles up to $30 \times 30 \mu \mathrm{m}$. On the other hand, the iron particles on the copper electrode reach significantly smaller dimensions and only up to $5 \times 5 \mu \mathrm{m}$.

Some of the electrodes used were more damaged by the machining process, as shown in Fig. 4, and deep holes of approximately $30 \times 10 \mu \mathrm{m}$ were formed, where the material was completely missing or cracks appeared. It was a copper and graphite electrode, so it cannot be said that the occurrence of defects is only a matter of one type of electrode eroding material. The erosion cracks on the electrodes have not been documented in similar studies so far, so, unfortunately, they cannot be compared with others. The defects in the electrode surface can mean a major problem especially in the production of very precise shapes where the highest quality of the machined surface is required. 


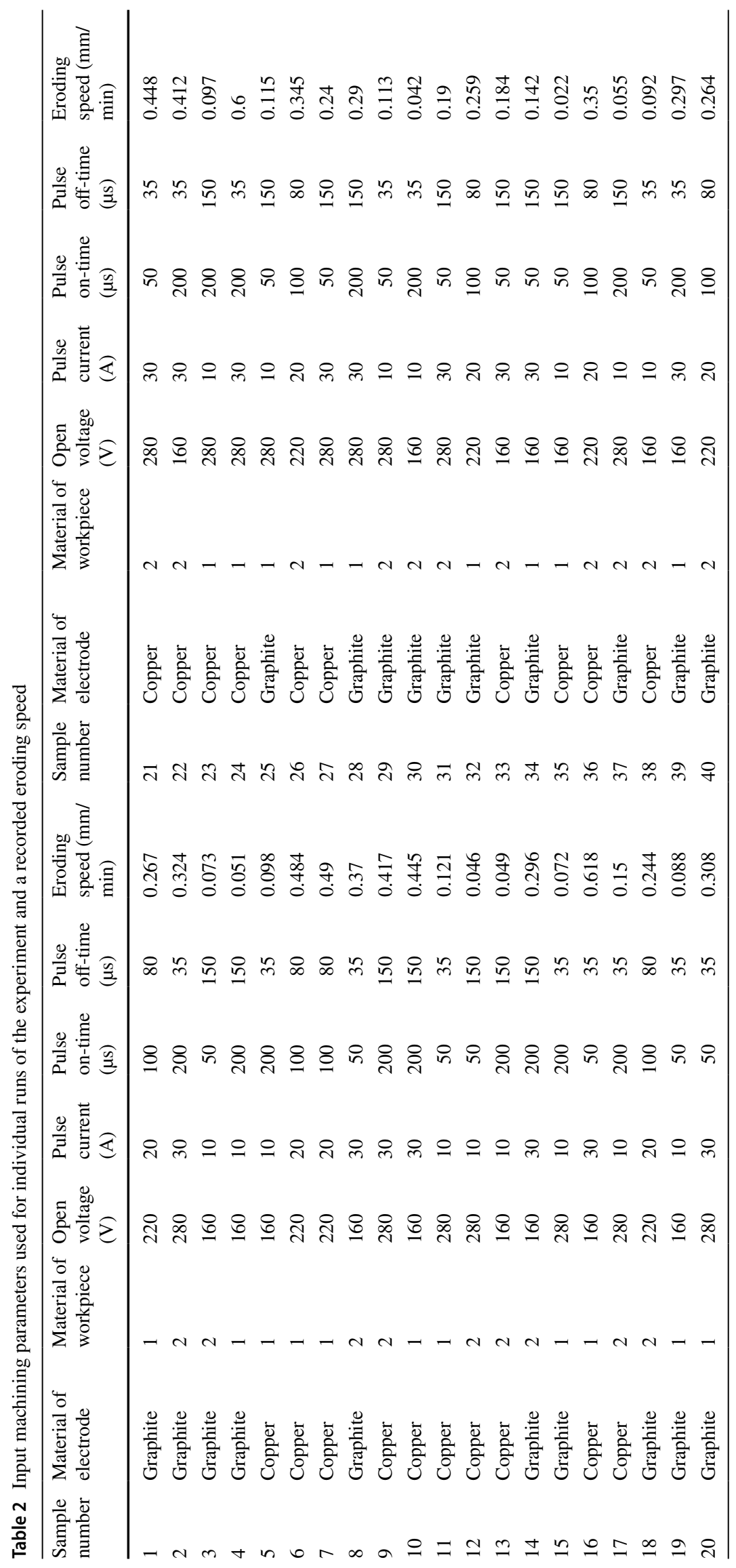



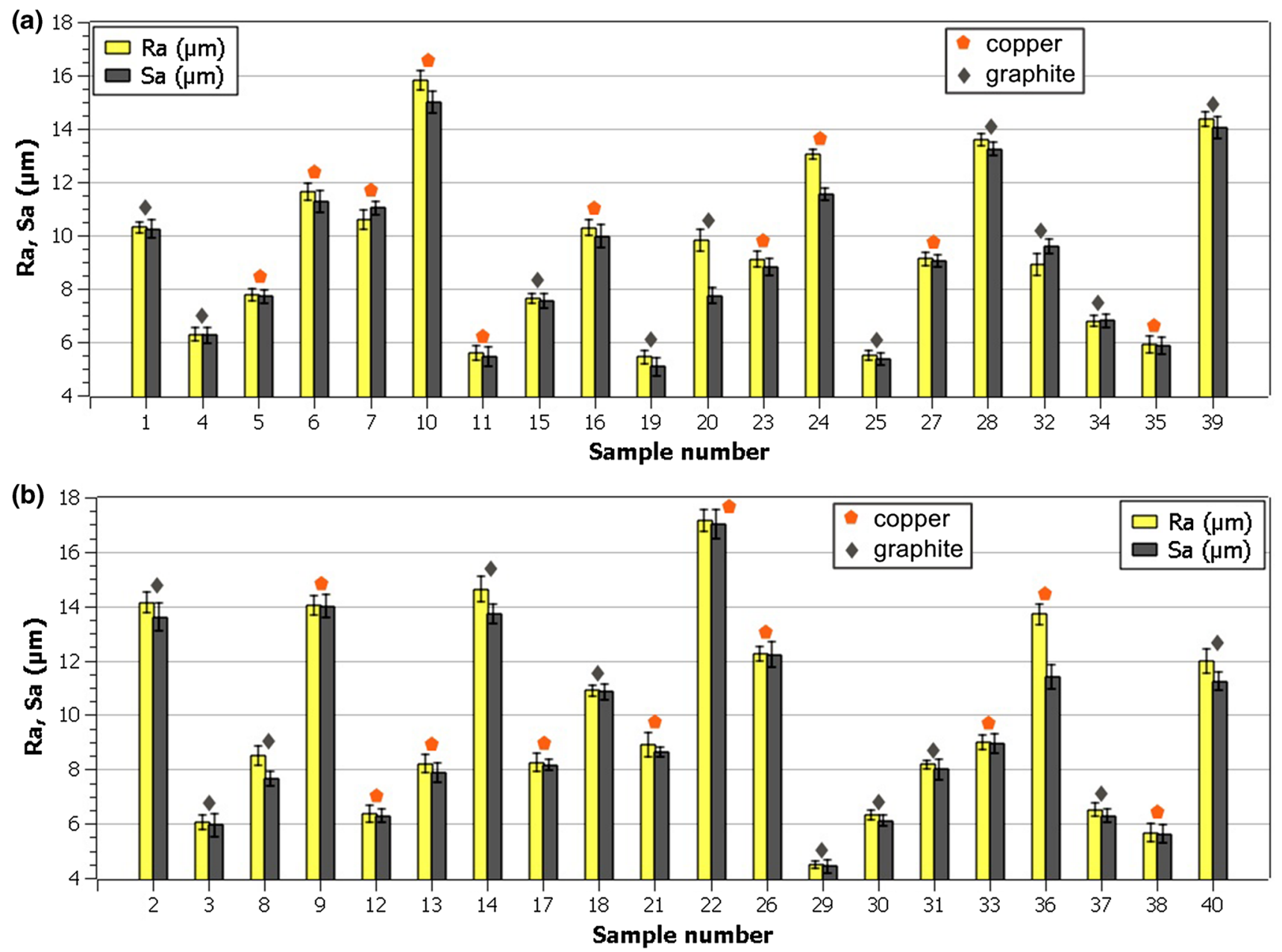

Fig. 2 The evaluated parameters Ra and Sa of individual experimental samples indicating the type of the material of the used electrode and 95\% confidence interval for mean a samples from material 1.2363 and $\mathbf{b}$ samples from material 1.2343ESR

\subsection{The precision analysis of the machined shapes}

The analysis of the accuracy of the machined shapes on all samples was always evaluated in cross section of each sample (the samples were cut by a metallographic saw) at both corners using an approximation circle. The radii of the individual approximation circles, i.e., the radii on the produced samples, were measured according to Fig. 5a and their values are graphed for both machined materials in Fig. 5b. Since the radius $R$ is measured, these observations do not have a standard deviation as an individual value, but the standard deviation from the analysis of the measurement system can be reported. The basis of this method is a one-way ANOVA. If we look at the measurement of the radius in the second corner as a repeated measurement of the same quantity, formula (1) can be derived for the standard deviation $s$, where $x, y_{i}$ are repeated measurements of the sample $i$ and $n$ is the number of measured samples: $s=\sqrt{\frac{\sum_{i=1}^{n}\left(x_{i}-y_{i}\right)^{2}}{2 n}}$.

The standard deviation of the repeatability of the radius measurement was $s(R)=11.195 \mu \mathrm{m}$, with the measurement system capable.

In all cases, a secondary electron detector was used for the imaging, with samples always studied at a magnification of 150x. The graphs (Fig. 5c,d) show that the smallest eroded radii were made with graphite electrodes. In all samples, the radii at each corner do not differ much from each other; only in Sample 15, this difference was more pronounced. This could probably be caused by poor electrode clamping during erosion. 
Fig. 3 SEM (SE) electrode surface morphology including the chemical composition analysis a a graphite electrode used for machining of 1.2343ESR steel with the setting of machine parameters according to Sample $37(U=280 \mathrm{~V}, I=10$ A, $T_{\text {on }}=200 \mu \mathrm{s}, T_{\text {off }}=150 \mu \mathrm{s}$ ); (b) copper electrode used for machining of 1.2343ESR steel with the machine parameter setting according to Sample $38(U=160 \mathrm{~V}, I=10 \mathrm{~A}$, $\left.T_{\text {on }}=50 \mu \mathrm{s}, T_{\text {off }}=35 \mu \mathrm{s}\right)$
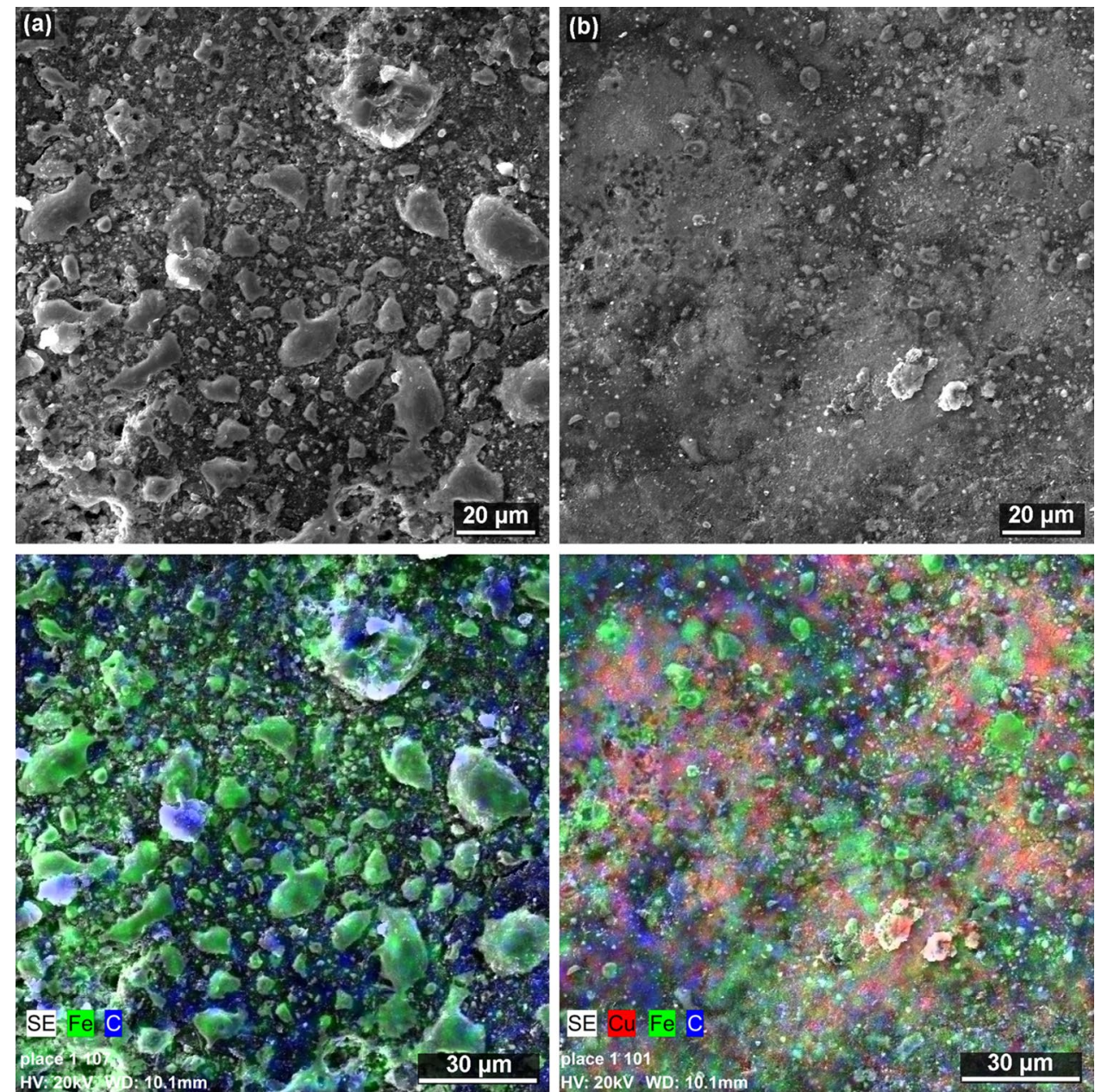

\subsection{Analysis of electrode wear in corners and edges}

The wear analysis of copper and graphite electrodes has been the subject of several studies, such as [6, 8], or [24], but in all of them, the wear was assessed for electrode weight comparison before and after machining. However, this methodology did not allow any assessment of wear at the electrode corners, and therefore, it was not possible to determine how the desired final shape of the workpiece would be degraded. Moreover, in the Khan study [8], electrode wear was assessed at $x$ and $y$ distance at only four corners of the electrode, and the other four edges according to this publication were not worn at all. On the basis of our research, this seems impractical. For this reason, a methodology has been used that clearly determines the wear in the corners of the individual electrodes used, including all four edges that are in direct contact with the workpiece. Using the electron microscopy, images were taken of two corners of each electrode (Fig. 4) and an approximation circle was then guided through them. The measure of wear in this study is the radius of this circle. All electrodes were at the same distance from the lens and $10 \mathrm{~mm}$ at the same magnification of 200x. The measured values of both corners for each electrode are shown in Table 3. Because wear $W$ is measured, as an individual value, these observations do not have a standard deviation. However, it is possible to state the standard deviation from the analysis of the measurement system, and the basis of this method is a one-way ANOVA. If we look at the measurement of wear in the second corner as a repeated measurement of the same quantity, the standard deviation can be calculated from formula (1). The standard deviation of the repeatability of the wear measurement was $s(W)=7.287 \mu \mathrm{m}$ and the measurement system is capable.

In either case, the two corner measurements did not deviate by more than $18 \mu \mathrm{m}$. In Fig. 5a, it is evident that machining has not only resulted in a loss of electrode material but also an increase and deformation at the corner and edge of the electrode. This deformation was caused by the increased adherence of iron eroded from the workpiece, as shown in Fig. 3a. Figure 6 shows the corners of the electrodes with the least wear.

It is clear from Table 3 that the lowest wear values for both materials were achieved using graphite electrodes. The copper electrodes are therefore more worn out in most cases, 
Fig. 4 SEM (SE) electrode surface morphology a a copper electrode used for machining of 1.2343ESR steel with machine parameter settings according to Sample $17-U=280 \mathrm{~V}, I=10$

A, $T_{\text {on }}=200 \mu \mathrm{s}$, and $T_{\text {off }}=35 \mu \mathrm{s}$; b a copper electrode used in machining of 1.2363 steel with machine parameter settings according to Sample $23-U=280 \mathrm{~V}, I=10 \mathrm{~A}$, $T_{\text {on }}=200 \mu \mathrm{s}$, and $T_{\text {off }}=150 \mu \mathrm{s}$; c a graphite electrode used in machining of $1.2343 \mathrm{ESR}$ with machine parameter settings according to Sample $37-U=280 \mathrm{~V}, I=10 \mathrm{~A}$, $T_{\text {on }}=200 \mu \mathrm{s}$, and $T_{\text {off }}=150 \mu \mathrm{s}$; d a copper electrode used in machining of 1.2343ESR with machine parameters set according to Sample $38-U=160 \mathrm{~V}$, $I=10 \mathrm{~A}, T_{\mathrm{on}}=50 \mu \mathrm{s}$, and $T_{\text {off }}=35 \mu \mathrm{s}$
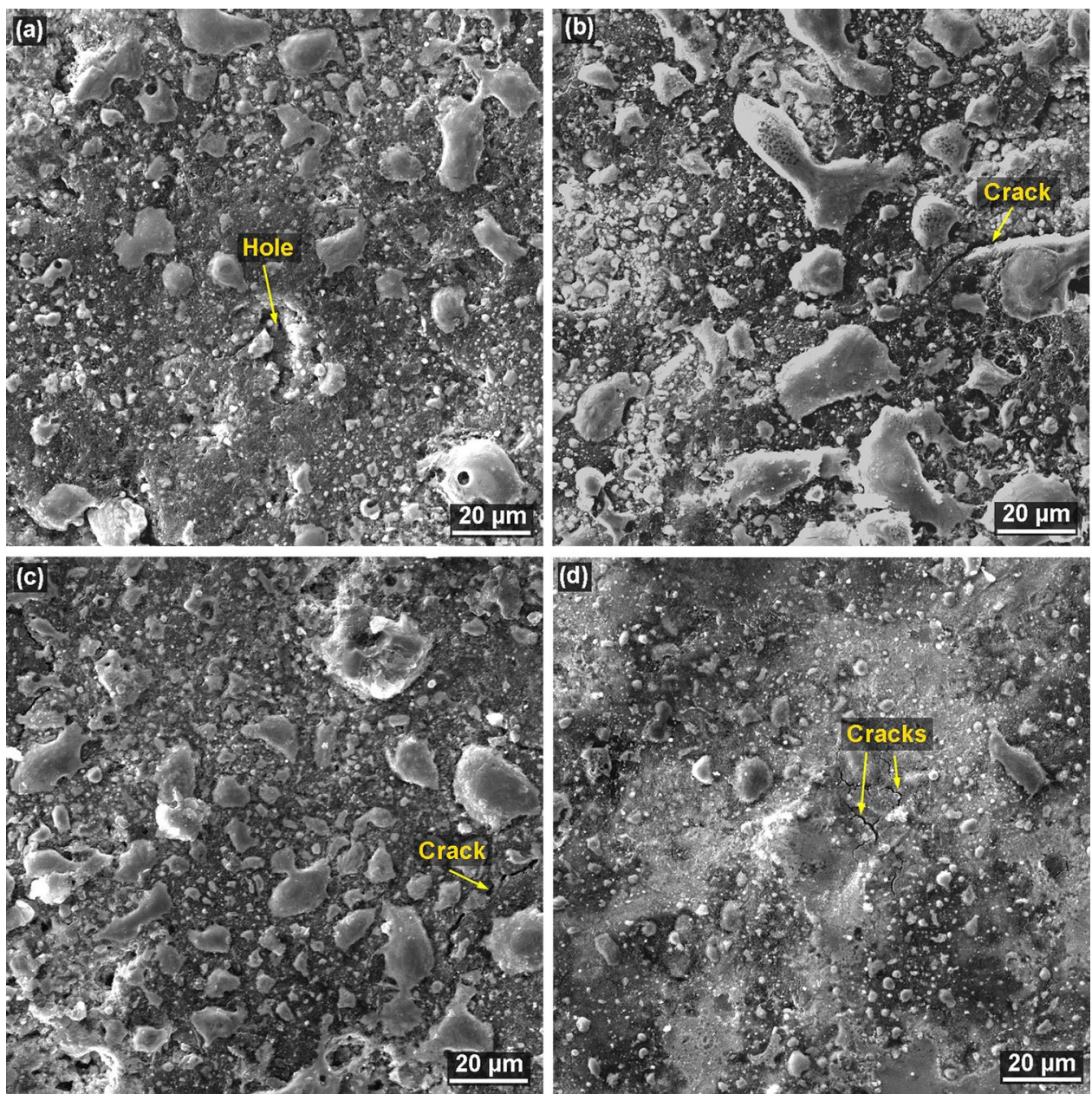

but there are also parameter settings that result in less wear almost comparable to the graphite electrode, which is evident when machining 1.2343ESR with machine parameter settings for Sample 17 ( $U=280 \mathrm{~V}, I=10 \mathrm{~A}, T_{\mathrm{on}}=200 \mu \mathrm{s}$, and $T_{\text {off }}=35 \mu \mathrm{s}$ ).

Thanks to two measurements at each DoE point, the socalled "false replication" of the whole experiment was generated (although 40 additional samples were not produced, we have two observations for each setting). The first task was to compare these "false replications" with each other. For this purpose, the median wear difference versus $0 \mu \mathrm{m}$ was tested (the null hypothesis is that there is no significant difference between wear at corner 1 and wear at corner 2). The point estimate of the median difference, in this case, is $0.5 \mu \mathrm{m}$ and both commonly used non-parametric methods (Wilcoxon test $-p$ value of 0.999 ; Sign test $-p$ value of 0.856 ) do not reject this hypothesis. Therefore, there is no point in distinguishing between different corners, and in the next, the data will be treated as two complete replications of the basic factorial design of the experiment.

In this case, the measurements at the central point serve only to detect the presence of a statistically significant curvature within the area of interest. The curvature tested in this way is statistically insignificant ( $p$ value $=0.606$ ), and thus, the curvature represented by the squares of individual input factor will not be included in the model. The consequence of insignificant curvature will be that any regression model created by DoE can have an extreme only at the boundary of the area of interest.

Before the modeling itself, it is necessary to realize that the half factor DoE used is a VI resolution and according to the identifying identity in the DoE, there will be the interchangeable effects of a constant with sixth-order interaction, first-order members with fifth-order interactions, secondorder interaction with the fourth-order interactions, and a pair of third-order interactions with each other. Therefore, it makes no sense to try to use higher order interaction in the model and only regressors up to and including order 2 will be considered. If the stepwise method is used to select statistically significant regressors with a 5\% significance level in both testing input and regressor rejection (requiring a hierarchical model at each step), the mathematical model will contain all first-order members and six second-order interactions except the constant. The Pareto graph of standardized 

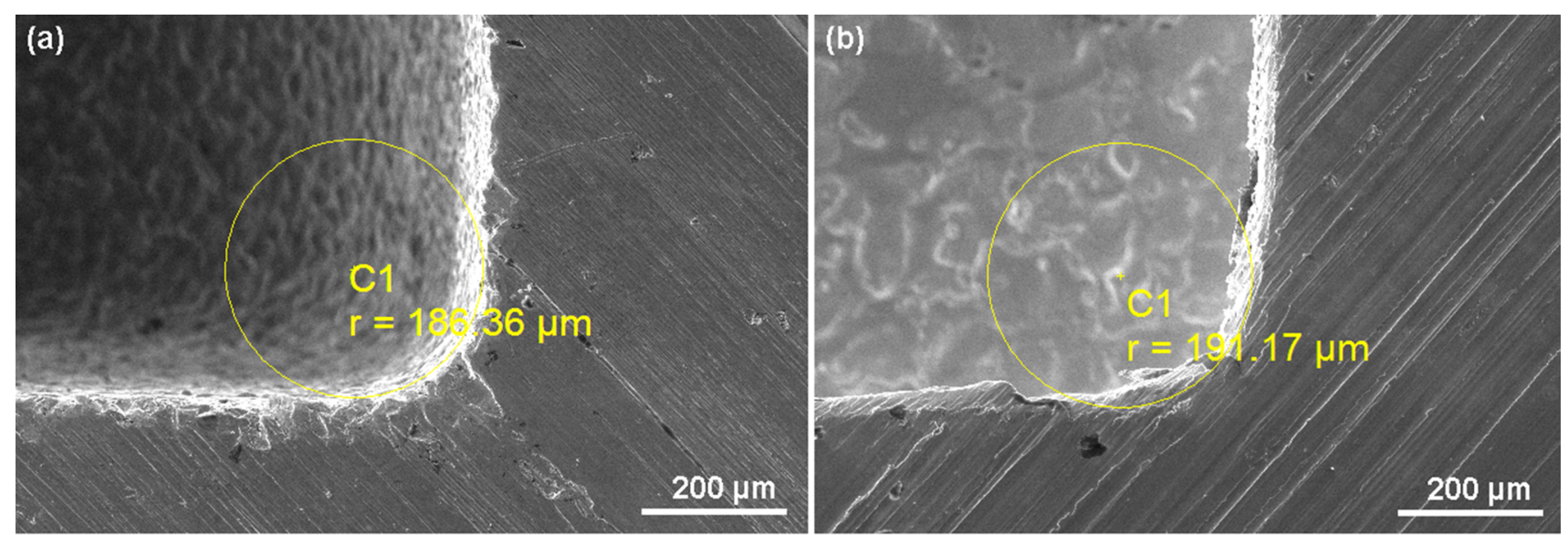

(c)

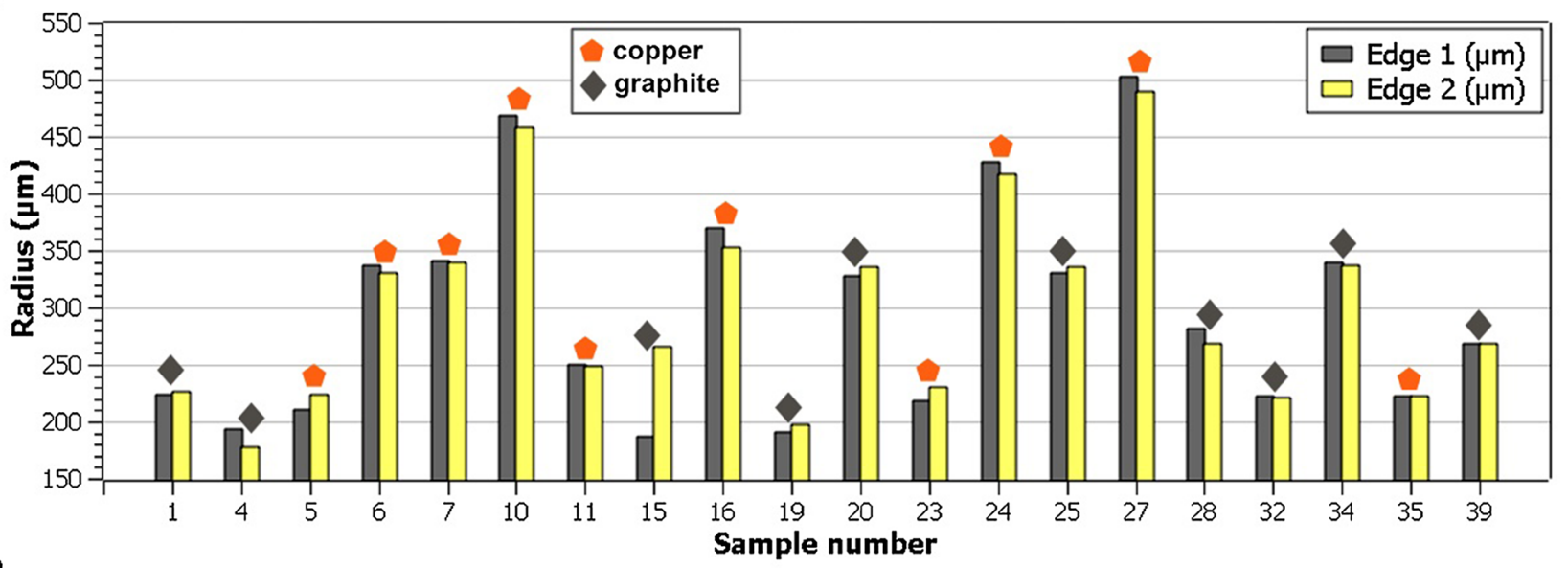

(d)

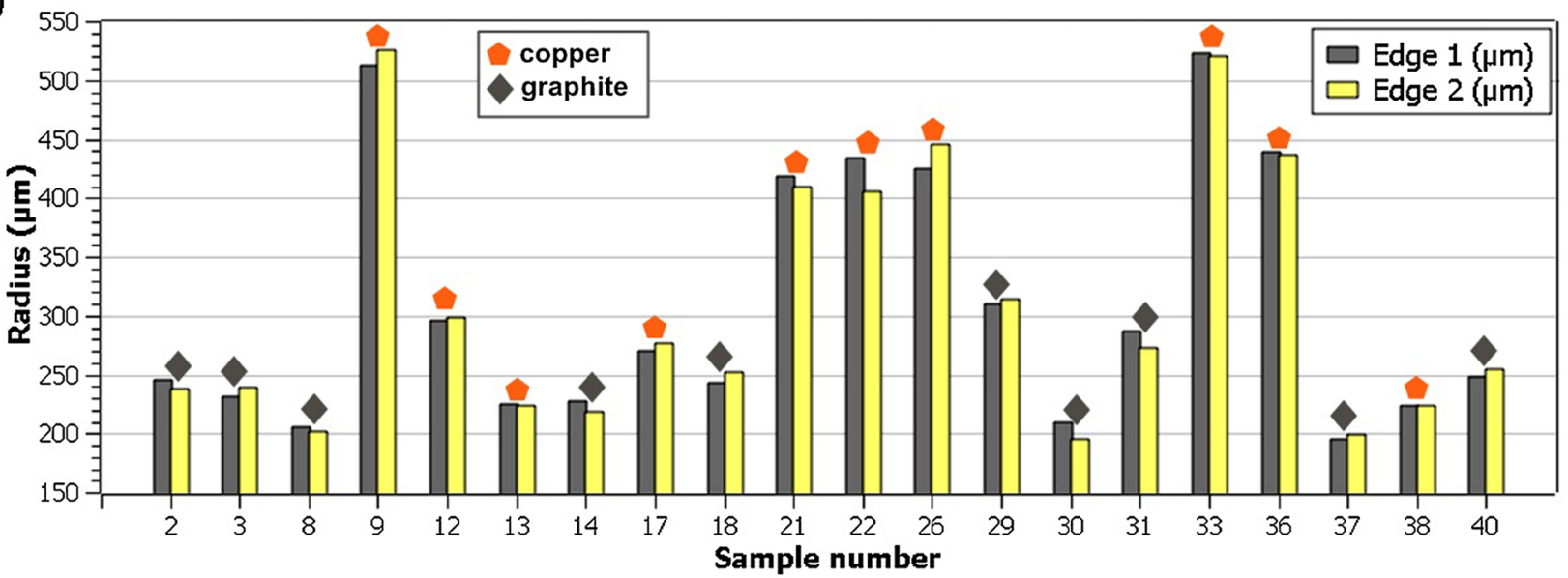

Fig. 5 a The radius of Sample $4-U=160 \mathrm{~V}, I=10 \mathrm{~A}, T_{\mathrm{on}}=200 \mu \mathrm{s}$, and $T_{\text {off }}=150 \mu \mathrm{s} ; \mathbf{b}$ the radius of Sample $37-U=280 \mathrm{~V}, I=10 \mathrm{~A}$, $T_{\text {on }}=200 \mu \mathrm{s}$, and $T_{\text {off }}=150 \mu \mathrm{s}$; $\mathbf{c}$ values of eroded radii for the sam-

effects (Fig. 7a) shows that the material, the pulse current used, and their interaction have the most significant impact on electrode wear.

The presence of interactions of categorical variables with continuous factors indicates that the response areas for each category will not differ only by a constant. On the other ples made of 1.2363 material; $\mathbf{d}$ values of eroded radii for the samples made of 1.2343ESR material

hand, a "small" (though statistically) significant effect of continuous factor interactions will result in a response area very similar to the four $4 \mathrm{D}$ super planes. Given the presence of categorical variables, it will be best to describe this linear regression model by four equations (each combination of categorical variable values will have its own equation). 
Table 3 Wear values of corners and edges of individual electrodes

\begin{tabular}{|c|c|c|c|c|c|c|c|c|c|}
\hline $\begin{array}{l}\text { Sample } \\
\text { number }\end{array}$ & $\begin{array}{l}\text { Material of } \\
\text { electrode }\end{array}$ & $\begin{array}{l}\text { Material of } \\
\text { workpiece }\end{array}$ & $\begin{array}{l}\text { Wear in the } \\
\text { corner } 1 \\
(\mu \mathrm{m})\end{array}$ & $\begin{array}{l}\text { Wear in the } \\
\text { corner } 2 \\
(\mu \mathrm{m})\end{array}$ & $\begin{array}{l}\text { Sample } \\
\text { number }\end{array}$ & $\begin{array}{l}\text { Material of } \\
\text { electrode }\end{array}$ & $\begin{array}{l}\text { Material of } \\
\text { workpiece }\end{array}$ & $\begin{array}{l}\text { Wear in the } \\
\text { corner } 1 \\
(\mu \mathrm{m})\end{array}$ & $\begin{array}{l}\text { Wear in the } \\
\text { corner } 2 \\
(\mu \mathrm{m})\end{array}$ \\
\hline 1 & Graphite & 1.2363 & 109 & 117 & 21 & Copper & 1.2343ESR & 310 & 301 \\
\hline 2 & Graphite & 1.2343ESR & 180 & 167 & 22 & Copper & 1.2343ESR & 300 & 310 \\
\hline 3 & graphite & 1.2343ESR & 140 & 142 & 23 & Copper & 1.2363 & 145 & 141 \\
\hline 4 & Graphite & 1.2363 & 132 & 119 & 24 & Copper & 1.2363 & 234 & 220 \\
\hline 5 & Copper & 1.2363 & 175 & 190 & 25 & Graphite & 1.2363 & 176 & 164 \\
\hline 6 & Copper & 1.2363 & 299 & 297 & 26 & Copper & 1.2343ESR & 257 & 248 \\
\hline 7 & Copper & 1.2363 & 297 & 296 & 27 & Copper & 1.2363 & 305 & 310 \\
\hline 8 & Graphite & 1.2343ESR & 148 & 143 & 28 & Graphite & 1.2363 & 139 & 152 \\
\hline 9 & Copper & 1.2343ESR & 251 & 264 & 29 & Graphite & 1.2343ESR & 171 & 159 \\
\hline 10 & Copper & 1.2363 & 266 & 281 & 30 & Graphite & 1.2343ESR & 148 & 145 \\
\hline 11 & Copper & 1.2363 & 207 & 208 & 31 & Graphite & 1.2343ESR & 218 & 204 \\
\hline 12 & Copper & 1.2343ESR & 153 & 165 & 32 & Graphite & 1.2363 & 112 & 115 \\
\hline 13 & Copper & 1.2343ESR & 150 & 152 & 33 & Copper & 1.2343ESR & 380 & 372 \\
\hline 14 & Graphite & 1.2343ESR & 143 & 138 & 34 & Graphite & 1.2363 & 209 & 199 \\
\hline 15 & Graphite & 1.2363 & 134 & 116 & 35 & Copper & 1.2363 & 169 & 166 \\
\hline 16 & Copper & 1.2363 & 351 & 338 & 36 & Copper & 1.2343ESR & 250 & 257 \\
\hline 17 & Copper & 1.2343ESR & 124 & 128 & 37 & Graphite & 1.2343ESR & 106 & 111 \\
\hline 18 & Graphite & 1.2343ESR & 115 & 131 & 38 & Copper & 1.2343ESR & 139 & 139 \\
\hline 19 & Graphite & 1.2363 & 181 & 185 & 39 & Graphite & 1.2363 & 114 & 130 \\
\hline 20 & Graphite & 1.2363 & 173 & 195 & 40 & Graphite & 1.2343ESR & 118 & 127 \\
\hline
\end{tabular}
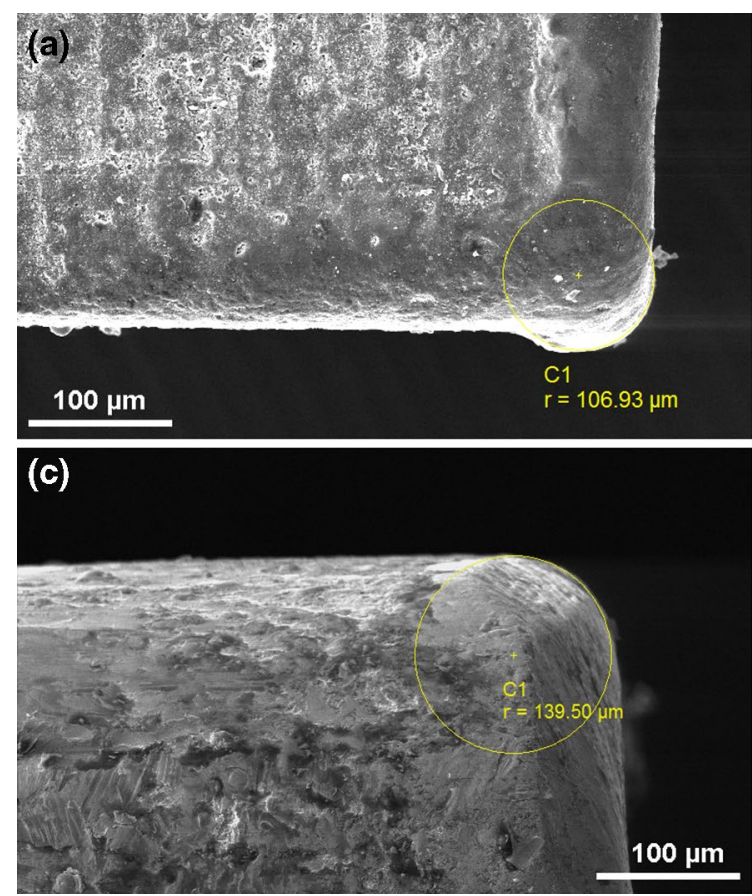

Fig. 6 Wear of corners and edges of SEM (SE) electrodes a graphite electrode used in machining of 1.2343ESR steel with the setting of machine parameters according to Sample $37-U=280 \mathrm{~V}, I=10 \mathrm{~A}$, $T_{\text {on }}=200 \mu \mathrm{s}$, and $T_{\text {off }}=150 \mu \mathrm{s} ; \mathbf{b}$ graphite electrode used in machining of 1.2363 steel with the setting of machine parameters according to Sample $1-U=220 \mathrm{~V}, I=20 \mathrm{~A}, T_{\text {on }}=100 \mu \mathrm{s}$, and $T_{\text {off }}=80 \mu \mathrm{s} ; \mathbf{c}$
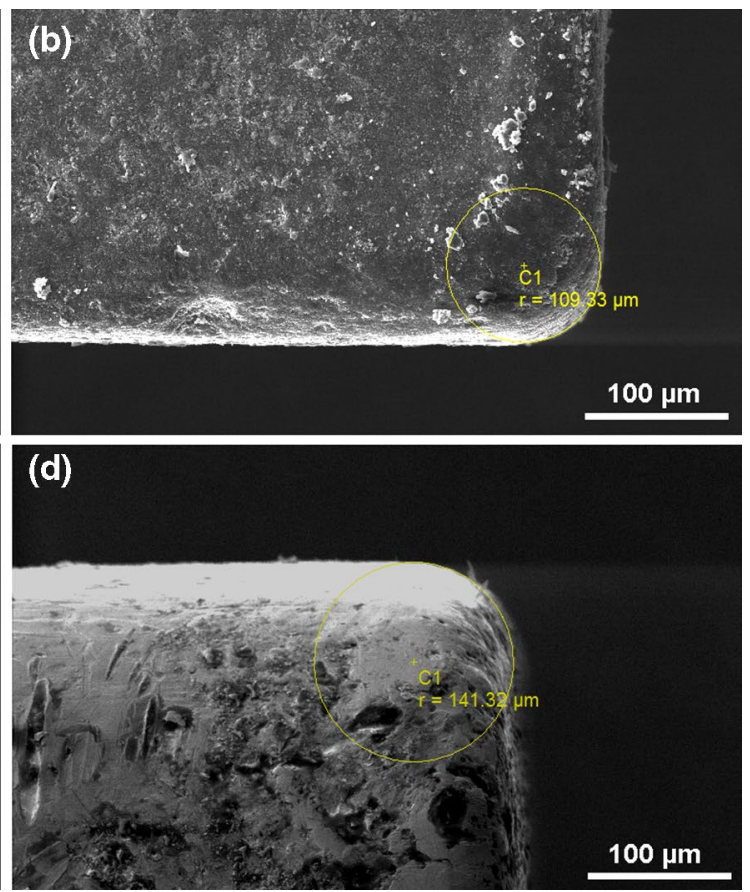

copper electrode used in machining of 1.2343ESR steel with the setting of machine parameters according to Sample $38-U=160 \mathrm{~V}$, $I=10 \mathrm{~A}, T_{\text {on }}=50 \mu \mathrm{s}$, and $T_{\text {off }}=35 \mu \mathrm{s} ; \mathbf{d}$ copper electrode used in machining of 1.2363 steel with the setting of machine parameters according to Sample $23-U=280 \mathrm{~V}, I=10 \mathrm{~A}, T_{\text {on }}=200 \mu \mathrm{s}$, and $T_{\text {off }}=150 \mu \mathrm{s}$ 
(a)
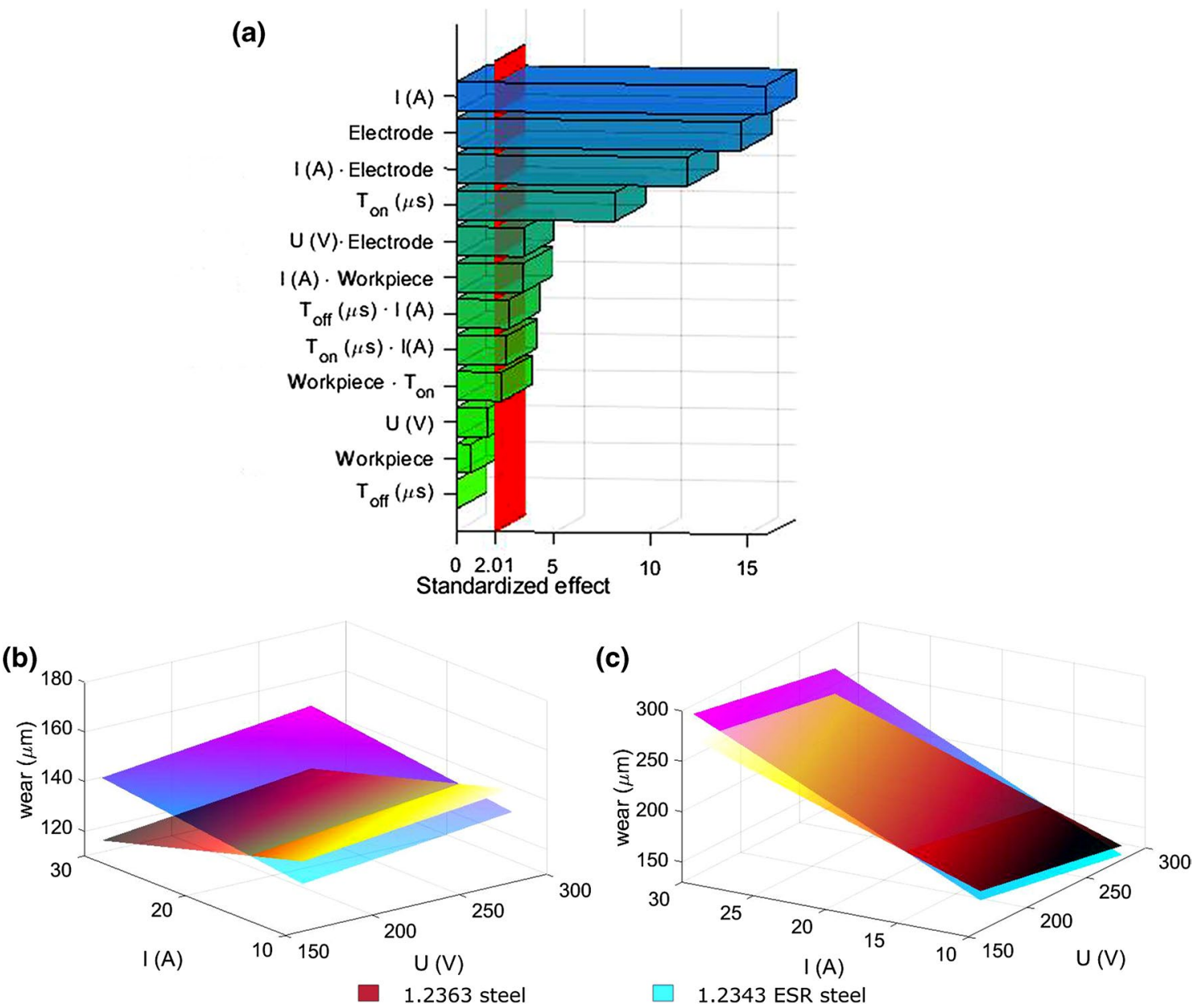

1.2343 ESR steel

Fig. 7. a A Pareto graph of the standardized regressor effects used in the wear model; $\mathbf{b}$ graphite electrode response areas; $\mathbf{c}$ copper electrode response areas

Equation (2) describing the mathematical wear model for graphite electrode and 1.2363 steel workpiece is as follows:

The regression model described by Eqs. (2)-(5) explains $87.62 \%$ of the observed wear variability (as

wear $=181.7+0.077 U+0.15 I-0.178 T_{\text {on }}-0.236 T_{\text {off }}-0.008 I \cdot T_{\text {on }}+0.011 I \cdot T_{\text {off }} \cdot$

Equation (3) describes the wear model for graphite electrode and 1.2343ESR steel workpiece: measured by the coefficient of determination). The response areas for pulse current and open voltage are

wear $=123.7+0.077 U+1.866 I-0.0009 T_{\text {on }}-0.236 T_{\text {off }}-0.008 I \cdot T_{\text {on }}+0.011 I \cdot T_{\text {off }}$.

Equation (4) describes the wear model for copper electrode and 1.2363steel workpiece: shown in Fig. 7b, c. To display these areas, it was necessary to fix the pulse on-time (200 $\mu$ s) and pulse off-time

wear $=199.9-0.214 U+6.146 I-0.178_{\text {on }}-0.236 T_{\text {off }}-0.008 I \cdot T_{\text {on }}+0.011 I \cdot T_{\text {off }}$.

Equation (5) describes the wear model for copper electrode and1.2343ESRsteel workpiece:
(35 $\mu$ s). Combinations of categorical variables are all displayed.

wear $=141.1-0.214 U+7.862 I-0.0009 T_{\text {on }}-0.236 T_{\text {off }} 0.008 I \cdot T_{\text {on }}+0.011 I \cdot T_{\text {off }} \cdot$ 
In Fig. 5b, c, it is clear that regardless of parameter setting, the graphite electrode wear will be lower than for the copper electrode. Furthermore, it can be seen that for the graphite electrode, the wear minimization setting is strongly dependent on the material being machined, while the copper electrode does not show this dependency.

During the experiment, in addition to electrode wear, other responses were observed, such as the eroding speed (shown in Table 2) and the surface topography (especially the Ra parameter). The Spearman correlation coefficient, which measures the monotonic dependence rate, was used as a measure of dependence and, unlike the classic Pearson correlation coefficient, does not require the data from the two-dimensional normal distribution while a statistical significance of dependence test.

Figure 8a shows the corresponding Spearman correlation coefficients including $p$ values. It can be seen here that each electrode behaves differently. While graphite electrode wear is independent of eroding speed and the Ra parameter ( $p$ value $>0.05$ ), copper electrode wear is dependent on eroding

(a)

\begin{tabular}{|c|c|c|c|}
\hline \multicolumn{4}{|c|}{ a) Electrode=graphite and copper } \\
\hline & Eroding speed & $\mathrm{Ra}(\mu \mathrm{m})$ & Radius $(\mu \mathrm{m})$ \\
\hline $\begin{array}{l}\text { Wear }(\mu \mathrm{m}) \\
\text { Spearman rho }\end{array}$ & 0.509 & 0.222 & 0.732 \\
\hline $\begin{array}{l}\text { Wear ( } \mu \mathrm{m}) \\
\text { P-Value }\end{array}$ & 0.000 & 0.061 & 0.000 \\
\hline \multicolumn{4}{|c|}{ b) Electrode = graphite } \\
\hline & Eroding speed & $\operatorname{Ra}(\mu \mathrm{m})$ & Radius $(\mu \mathrm{m})$ \\
\hline $\begin{array}{l}\text { Wear }(\mu \mathrm{m}) \\
\text { Spearman rho }\end{array}$ & 0.173 & -0.249 & 0.497 \\
\hline $\begin{array}{l}\text { Wear }(\mu \mathrm{m}) \\
\text { P-Value }\end{array}$ & 0.313 & 0.143 & 0.002 \\
\hline \multicolumn{4}{|c|}{ c) Electrode = copper } \\
\hline & Eroding speed & $\operatorname{Ra}(\mu \mathrm{m})$ & Radius $(\mu \mathrm{m})$ \\
\hline $\begin{array}{l}\text { Wear }(\mu \mathrm{m}) \\
\text { Spearman rho }\end{array}$ & 0.694 & 0.545 & 0.729 \\
\hline $\begin{array}{l}\text { Wear }(\mu \mathrm{m}) \\
\text { P-Value }\end{array}$ & 0.000 & 0.001 & 0.000 \\
\hline
\end{tabular}

(b)

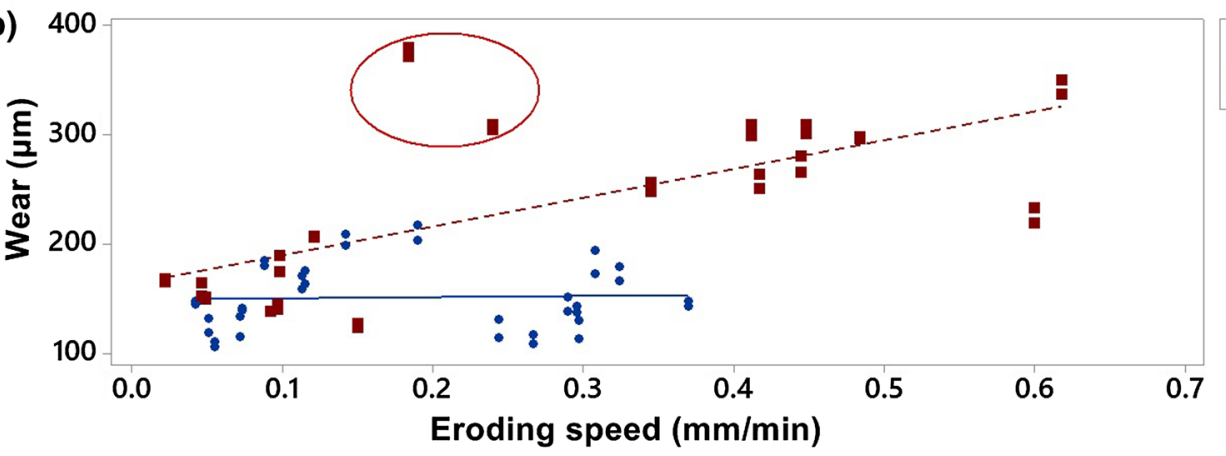

Electrode - copper $-\rightarrow-$ graphite

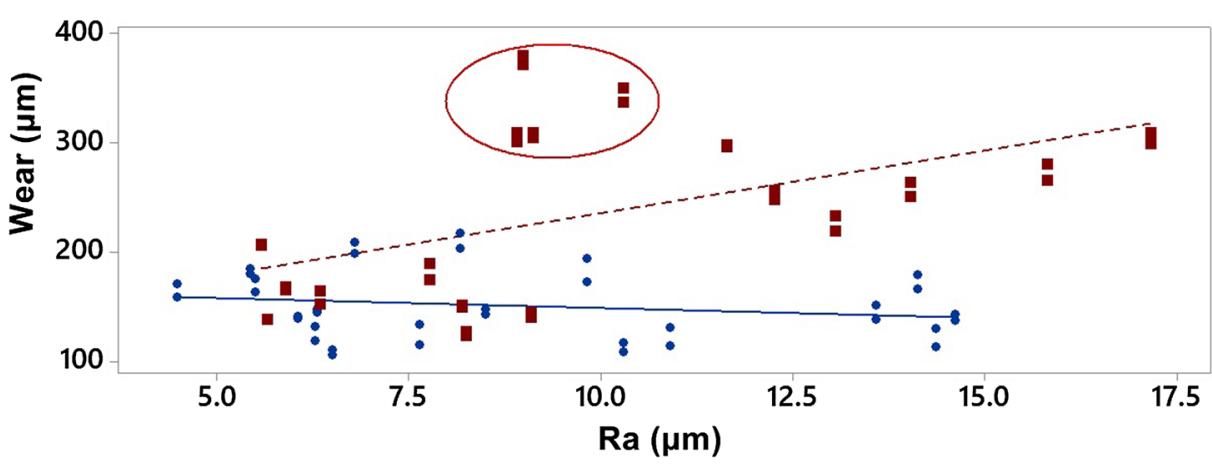

Fig. 8 a Spearman correlation coefficient for individual response dependence; $\mathbf{b}$ influence of electrode material on wear at corners and other output parameters 
speed and the Ra topography parameter $(p$ value $<0.05)$. If we plot these dependencies (Fig. 8b), we can see that with the copper electrode, it is possible to achieve a higher eroding speed, but at the cost of increasing the Ra parameter. The settings marked with a red ellipse are inappropriate due to wear. This is where Pulse current was set to maximum and Pulse on-time was set to minimum for the copper electrode.

The dependence of wear on the pulse current for the copper electrode is consistent with the results from Khan [8] and Klocke [10] studies. For the graphite electrode, however, it is necessary to take into account interactions (especially with workpiece material) that are not studied in any of these studies. In contrast to the Kumar study [14], which described the effect of current as insignificant, the effect of this factor proved to be most significant. This fact can probably be explained by other machined material, which is consistent with the observed material-current interaction. In contrast, Torres [12] and Zarepour [24] studies detected a statistically significant quadratic curvature (the effect of squares explaining variables), but none of these studies focused on the effect of categorical variables (workpiece and electrode material). The presence of statistically significant curvature in these studies suggests the presence of a higher-order interaction with one of the categorical variables, which a possible suggestion for further research. A possible explanation for the differences in the models, however, maybe a different methodology for the wear observation.

\section{Conclusions}

Wear of copper and graphite electrodes was investigated in this study using a 40-round design of experiments, which took into account not only the type of machined material but also 4 machine setting parameters. Based on subsequent analyses and assessments, the following conclusions were reached:

- the lowest values of topography parameters were achieved during graphite electrode machining, for 1.2343ESRsteel for Sample $29(U=280 \mathrm{~V}, I=10 \mathrm{~A}$, $T_{\mathrm{on}}=50 \mu \mathrm{s}$, and $\left.T_{\mathrm{off}}=35 \mu \mathrm{s}\right)$, when the Ra value was only $4.4 \mu \mathrm{m}$ and for 1.2363 steel for Sample $19(U=160 \mathrm{~V}$, $I=10 \mathrm{~A}, T_{\text {on }}=50 \mu \mathrm{s}$, and $T_{\text {off }}=35 \mu \mathrm{s}$ ), where the Ra value was only $5.4 \mu \mathrm{m}$,

- significantly more eroded material from the workpiece adheres to graphite electrodes, but the burnt places formed by carbon have been studied on copper electrodes.

- one of the graphite and two copper electrodes have been damaged by cracks and holes in the working part of one copper electrode with dimensions of about $30 \times 10 \mu \mathrm{m}$,
- an analysis of the precision of the machined shapes has clearly shown that the most accurate machining and, hence, the smallest radius was achieved with graphite electrodes,

- mathematical models of electrode wear were developed, and the most important factor was the Pulse current setting parameter as well as the electrode material, either copper or graphite, with more wear on the copper electrodes,

- for graphite electrodes, the wear-minimizing setting is strongly dependent on the material being machined, while copper electrodes do not show this dependence,

- the wear of the graphite electrode is independent of the eroding speed and the parameter Ra; on the contrary, the wear of the copper electrode is dependent on them.

From the above conclusions, it is clear that using a graphite electrode, it is possible to achieve more accurate shapes of machined samples with a higher surface quality at a lower level of electrode wear than using a copper electrode.

Funding This work was supported by the Technology Agency of the Czech Republic, project no. TJ02000311. CzechNanoLab project LM2018110 funded by MEYS CR is gratefully acknowledged for the financial support of the measurements/sample fabrication at CEITEC Nano Research Infrastructure. This work was supported by the Brno University of Technology Specific Research Program, project no. FSI-S-17-4464.

\section{Compliance with ethical standards}

Conflict of interest Authors K. Mouralova, J. Bednar, L. Benes, P. Hrabec, M. Kalivoda, and J. Fries declare that they have no conflict of interest.

\section{References}

1. Meshram DB, Puri YM. Review of research work in die sinking EDM for machining curved hole. J Braz Soc Mech Sci Eng. 2017;39(7):2593-605.

2. Khan D, Goswami H, Somkuwar V. Process parameter optimization of die sinking EDM: a review. Int Res J Eng Technol. 2018;5:1493-500.

3. Singh NK, Pandey PM, Singh KK, Sharma MK. Steps towards green manufacturing through EDM process: a review. Cogent Eng. 2016;3(1):1272662.

4. Selvarajan L, Rajavel J, Prabakaran V, Sivakumar B, Jeeva G. A review paper on EDM parameter of composite material and industrial demand material machining. Mater Today Proc. 2018;5(2):5506-13.

5. Bleys P, Kruth JP, Lauwers B, Zryd A, Delpretti R, Tricarico C. Real-time tool wear compensation in milling EDM. CIRP Ann. 2002;51(1):157-60. 
6. Luis CJ, Puertas I, Villa AG. Material removal rate and electrode wear study on the EDM of silicon carbide. J Mater Process Technol. 2005;164:889-96.

7. Tsai YY, Masuzawa T. An index to evaluate the wear resistance of the electrode in micro-EDM. J Mater Process Technol. 2004;149(1-3):304-9.

8. Khan AA. Electrode wear and material removal rate during EDM of aluminum and mild steel using copper and brass electrodes. Int J Adv Manuf Technol. 2008;39(5-6):482-7.

9. Narasimhan J, Yu Z, Rajurkar KP. Tool wear compensation and path generation in micro and macro EDM. J Manuf Process. 2005;7(1):75-82.

10. Klocke F, Schwade M, Klink A, Veselovac D. Analysis of material removal rate and electrode wear in sinking EDM roughing strategies using different graphite grades. Procedia CIRP. 2013;6:163-7.

11. Yin Q, Wang B, Zhang Y, Ji F, Liu G. Research of lower tool electrode wear in simultaneous EDM and ECM. J Mater Process Technol. 2014;214(8):1759-68.

12. Torres A, Luis CJ, Puertas I. Analysis of the influence of EDM parameters on surface finish, material removal rate, and electrode wear of an INCONEL 600 alloy. Int J Adv Manuf Technol. 2015;80(1-4):123-40.

13. Maradia U, Boccadoro M, Stirnimann J, Kuster F, Wegener K. Electrode wear protection mechanism in meso-micro-EDM. J Mater Process Technol. 2015;223:22-33.

14. Kumar NM, Kumaran SS, Kumaraswamidhas LA. An investigation of mechanical properties and material removal rate, tool wear rate in EDM machining process of AL2618 alloy reinforced with Si3N4, AlN and ZrB2 composites. J Alloy Compd. 2015;650:318-27.

15. Mouralova K, Prokes T, Benes L, Bednar J. The influence of WEDM parameters setup on the occurrence of defects when machining Hardox 400 Steel. Materials. 2019;12(22):3758.

16. Mouralova K, Prokes T, Benes L, Sliwkova P. Analysis of subsurface defects occurrence in abrasion resistant Creusabro steel after WEDM including the study of morphology and surface topography. Mach Sci Technol. 2019;24:1-17.
17. Mouralova K, Klakurkova L, Matousek R, Prokes T, Hrdy R, Kana V. Influence of the cut direction through the semi-finished product on the occurrence of cracks for X210Cr12 steel using WEDM. Arch Civ Mech Eng. 2018;18(4):1318-31.

18. Mouralova K, Benes L, Prokes T, Bednar J, Zahradnicek R, Jankovych R, Vontor J. Analysis of the machinability of copper alloy ampcoloy by WEDM. Materials. 2020;13(4):893.

19. Geometrical Product Specifications (GPS) -Surface texture: Areal -Part 2: Terms, definitions and surface texture parameters. ISO 25178-2 (2012). Geneva: International Organization for Standardization.

20. Geometrical Product Specifications (GPS) -Surface texture: Profile method -Terms, definitions and surface texture parameters. ISO 4287 (1997). Geneva: International Organization for Standardization.

21. Kiyak M, Çakır O. Examination of machining parameters on surface roughness in EDM of tool steel. J Mater Process Technol. 2007;191(1-3):141-4.

22. Amorim FL, Weingaertner WL. The behavior of graphite and copper electrodes on the finish die-sinking electrical discharge machining (EDM) of AISI P20 tool steel. J Braz Soc Mech Sci Eng. 2007;29(4):366-71.

23. Bleys P, Kruth JP, Lauwers B, Schacht B, Balasubramanian V, Froyen L, Van Humbeeck J. Surface and sub-surface quality of steel after EDM. Adv Eng Mater. 2006;8(1-2):15-25.

24. Zarepour H, Tehrani AF, Karimi D, Amini S. Statistical analysis on electrode wear in EDM of tool steel DIN 12714 used in forging dies. J Mater Process Technol. 2007;187:711-4.

25. Ho KH, Newman ST. State of the art electrical discharge machining (EDM). Int J Mach Tools Manuf. 2003;43(13):1287-300.

Publisher's Note Springer Nature remains neutral with regard to jurisdictional claims in published maps and institutional affiliations. 